\title{
Resource utilisation and costs associated with the treatment of diabetic foot ulcers. Prospective data from the Eurodiale Study
}

\author{
L. Prompers • M. Huijberts $\cdot$ N. Schaper • J. Apelqvist • \\ K. Bakker • M. Edmonds $\cdot$ P. Holstein $\cdot$ E. Jude $\cdot$ \\ A. Jirkovska • D. Mauricio • A. Piaggesi • H. Reike • \\ M. Spraul $\cdot$ K. Van Acker $\cdot$ S. Van Baal . \\ F. Van Merode $\cdot$ L. Uccioli • V. Urbancic • \\ G. Ragnarson Tennvall
}

Received: 17 May 2008 / Accepted: 6 June 2008 / Published online: 22 July 2008

(C) The Author(s) 2008

\begin{abstract}
Aims/hypothesis The aim of the present study was to investigate resource utilisation and associated costs in patients with diabetic foot ulcers and to analyse differences in resource utilisation between individuals with or without peripheral arterial disease (PAD) and/or infection.

Methods Data on resource utilisation were collected prospectively in a European multicentre study. Data on 1,088 patients were available for the analysis of resource use, and
\end{abstract}

L. Prompers $(\bowtie) \cdot$ M. Huijberts $\cdot$ N. Schaper

Department of Internal Medicine, University Hospital Maastricht,

P. Debyelaan 25, P.O. Box 5800, 6202 AZ Maastricht,

the Netherlands

e-mail: Leonne.Prompers@intmed.unimaas.nl

J. Apelqvist

Department of Endocrinology, University of Malmö,

Malmö, Sweden

K. Bakker

Chair IDF Consultative Section and International

Working Group on the Diabetic Foot,

Heemstede, the Netherlands

M. Edmonds

Diabetic Department, Kings College Hospital,

London, UK

\section{P. Holstein}

Copenhagen Wound Healing Centre, Bispebjerg Hospital,

Copenhagen, Denmark

\section{E. Jude}

Diabetes Centre, Tameside General Hospital,

Ashton-under-Lyne, UK data on 821 patients were included in the costing analysis. Costs were calculated for each patient by multiplying the country-specific direct and indirect unit costs by the number of resources used from inclusion into the study up to a defined endpoint. Country-specific costs were converted into purchasing power standards.

Results Resource use and costs varied between outcome groups and between disease severity groups. The highest costs per patient were for hospitalisation, antibiotics,

A. Jirkovska

Diabetes Centre, Institute for Clinical and Experimental Medicine,

Prague, Czech Republic

D. Mauricio

Department of Endocrinology,

Hospital Universitari Arnau de Vilanova,

Lleida, Spain

A. Piaggesi

U.O. Semplice Piede Diabetico,

Dipartimento di Endocrinologia e Metabolismo,

Azienda Ospedaliera Universitaria Pisana,

Pisa, Italy

H. Reike

Innere Abteilung, Mariannen Hospital,

Werl, Germany

M. Spraul

Diabetic Department, Mathias-Spital,

Rheine, Germany

K. V. Acker

Diabetic Foot Unit, St Joseph Clinic,

Bornem, Belgium 
amputations and other surgery. All types of resource utilisation and costs increased with the severity of disease. The total cost per patient was more than four times higher for patients with infection and PAD at inclusion than for patients in the least severe group, who had neither.

Conclusions/interpretation Important differences in resource use and costs were found between different patient groups. The costs are highest for individuals with both peripheral arterial disease and infection, and these are mainly related to substantial costs for hospitalisation. In view of the magnitude of the costs associated with inhospital stay, reducing the number and duration of hospital admissions seems an attractive option to decrease costs in diabetic foot disease.

Keywords Costs $\cdot$ Diabetes $\cdot$ European $\cdot$ Foot ulcer . Multicentre $\cdot$ Prospective $\cdot$ Resource utilisation

\section{Abbreviations \\ Eurodiale European Study Group on Diabetes and the Lower Extremity \\ LEA lower extremity amputation \\ PAD peripheral arterial disease}

\section{Introduction}

Diabetic foot disease is a common complication of both type 1 and type 2 diabetes. The impact of diabetic foot disease is substantial; patients with diabetes developing foot ulcers have a low quality of life and treatment is often long and intensive [1]. In view of the increasing number of diabetic patients and limited healthcare resources, data on the cost of treatment are necessary to prioritise healthcare expenditures and to attempt to determine which patients and aspects of

\section{S. V. Baal}

Department of Surgery, Twenteborg Ziekenhuis,

Almelo, the Netherlands

F. V. Merode

Department of Health Organization, Policy and Economics, University of Maastricht,

Maastricht, the Netherlands

L. Uccioli

Policlinico Tor Vergata,

Rome, Italy

V. Urbancic

Department of Endocrinology, University Medical Centre,

Ljubljana, Slovenia

G. R. Tennvall

Swedish Institute for Health Economics (IHE),

Lund, Sweden treatment are the most important determinants of costs. Although only a minority of foot ulcers will result in a lower extremity amputation (LEA) [2], these amputations are associated with the highest costs. Studies from Sweden have demonstrated that the cost of treatment for a patient who healed after an amputation were about $€ 29,000-43,000$ in the 1990s, depending on the amputation level and whether or not the foot ulcer was infected [3-5]. A recent paper on a prospective Australian study reported that, on average, inpatient costs for LEA totalled AU\$17,089 [6].

Several retrospective single-centre studies, using different methodologies, have found that costs for foot ulcer treatment in general are also high [7-10]. The pathophysiology of diabetic foot disease is complex, and because several factors may play a role in the development of foot ulcers, the population of individuals presenting with diabetic foot ulcers is relatively heterogeneous. For instance, in a recently published paper by the European Study Group on Diabetes and the Lower Extremity (Eurodiale), in which patients were grouped according to the presence or absence of peripheral arterial disease (PAD) and/or infection, individuals with both PAD and infection were older, more often had severe comorbidity and frequently had larger ulcers at presentation, most of which were non-plantar [11]. Many of these factors also predicted non-healing [2], and poor healing is likely to be associated with high resource utilisation. Because the characteristics of patients who are treated in different diabetic foot units may vary, it is important to obtain prospective data on resource utilisation and associated costs in relation to specific patient characteristics. To put the cost of treatment into perspective, outcome data should also be taken into account.

The Eurodiale Study was a prospective, multicentre, observational study on patients with a diabetic foot ulcer. The design, baseline patient characteristics and clinical outcomes have been published elsewhere [2, 11, 12]. This project was also designed as a cost of treatment study, and its aim was to analyse resource utilisation and associated costs in a large cohort of well-characterised patients with diabetic foot ulcers and to determine the differences in resource utilisation between individuals with or without PAD and/or infection.

\section{Methods}

Study design and population

The Eurodiale consortium is a collaborative network of 14 European diabetic foot centres, created to stimulate research in the field of diabetic foot disease. The design and rationale of this study have been described in detail elsewhere [12]. Briefly, between 1 September 2003 and 1 
October 2004, patients presenting with a new foot ulcer at 14 diabetic foot centres in ten European countries enrolled in the study. A total of 1,232 patients with a new foot ulcer were enrolled into the study and 1,088 were followed until endpoint.

Subjects attended follow-up visits on a monthly basis until an endpoint or study end was reached. The endpoints were healing of the complete foot, major amputation and death. Definitions of the baseline characteristics have been published previously and are based on the Perfusion, Extent/size, Depth/tissue loss, Infection and Sensation (PEDIS) classification system [12, 13]. For the costing analysis, patients were grouped according to disease severity, as indicated by the presence or absence of PAD and/or infection (stages of the University of Texas wound classification system [14]). The main characteristics of all patients available for evaluation are presented in Table 1.

Informed consent and ethics committee approval

The study was approved by local ethics committees in all countries and all participants gave written informed consent.

Table 1 Patient characteristics at inclusion

\begin{tabular}{lc}
\hline Patient characteristics & $\begin{array}{c}\text { All patients available for evaluation } \\
n=1,088\end{array}$ \\
\hline Age (years) & \\
Sex & $65(24-95)$ \\
Male & $704(65)$ \\
Female & $384(35)$ \\
Ulcer duration at inclusion & \\
$<1$ week & $184(17)$ \\
$<3$ months & $625(57)$ \\
$>3$ months & $269(25)$ \\
Ulcer size at inclusion & \\
$<1.0 \mathrm{~cm}^{2}$ & $403(37)$ \\
$1.0-5.0 \mathrm{~cm}^{2}$ & $561(52)$ \\
$>5.0 \mathrm{~cm}^{2}$ & $117(11)$ \\
Depth of ulcer at inclusion & $612(56)$ \\
Superficial ulcer & $476(44)$ \\
Deep ulcer & \\
Comorbidity & $117(11)$ \\
Heart failure NYHA III-IV & $107(10)$ \\
Inability to stand or walk & $70(6)$ \\
without help & $164(15)$ \\
Neurological disorder & $63(6)$ \\
Visual impairment & \\
End-stage renal disease & \\
\hline
\end{tabular}

Number of patients in each category with percentage within parentheses except for the age variable. Values are presented as $n$ (\%) unless indicated otherwise. Values for every variable were not available for all evaluated patients

NYHA, New York Heart Association

${ }^{a}$ Values are presented as mean (range)

\section{Unit cost data}

Costing consists of two elements: measurement of the resources used and the assignment of unit costs. In the present study the analysis of resource utilisation for the management of patients with diabetic foot ulcers is based on the study data for all patients followed up to endpoint who were available for analysis $(n=1,088)$.

Given the high variability in underlying pathology and disease severity, only countries with at least 80 patients available for analysis were included in the cost analysis, to ensure that the data were reliable and representative. In addition, countries for which complete information about unit costs for every type of resource used could not be provided were excluded from the cost analysis.

For each country, unit cost data were collected from official pricelists or other national sources. The unit costs should, as far as possible, reflect the 'true' resource utilisation in each country. Therefore, the unit cost of a procedure, a drug or a visit to the clinic included the total cost, irrespective of who was responsible for paying all or part of the costs. The payer could be the patient, the hospital, an authority, an insurance company, or a combination.

The unit costs of all types of resources used in the management of diabetic foot ulcers were provided by participating centres from seven (Czech Republic, Denmark, Italy, the Netherlands, Slovenia, Sweden and the UK) of the ten participating countries, using a specific unit cost form. In total, $75 \%$ of the patients available for analysis $(n=821)$ were included in the economic analysis.

The unit cost form was based on the items listed in the entry and follow-up forms of the Eurodiale Study [12]. It contained questions about local currency, year of cost data, unit costs for inpatient and outpatient care, investigations, interventions, antibiotics, different types of staff, topical dressings, transport and the income of the general population. For each type of resource it was possible to include additional comments, e.g. if any unit cost referred to a year different from the majority of the other unit costs. In addition, the sources of the unit costs were given.

\section{Cost calculation}

Costs were calculated individually for each patient according to the resource utilisation indicated in the entry and follow-up forms. For each country, the utilisation of each type of resource was multiplied by the corresponding unit cost for the resource in that particular country. Costs were calculated from the entry date up to the date of the final visit. Any unrealistic values of resource utilisation have been checked and if necessary recoded to avoid overestimation of resource use and costs. 
Diagnostic procedures The costs for diagnostic procedures were calculated by multiplying the number of each type of procedure performed for a patient by the unit cost of that procedure. All costs were then added together to give a total cost per patient for diagnostic procedures.

Off-loading Off-loading costs were calculated by determining the total number of footwear, insoles, orthoses and casts prescribed for a patient and multiplying this by the unit cost for each type of off-loading. All costs were then added together a give a total cost per patient for off-loading.

Interventional procedures The costs for interventional procedures were calculated according to the number and type of procedures that were performed.

Antibiotic therapy The number of treatment days for each prescription for antibiotics was calculated by subtracting the start date from the end date of the prescription. The total number of treatment days per patient for all antimicrobial drugs were multiplied by the average daily cost for that specific drug at the centre or country used. For patients receiving more than one antibiotic drug simultaneously, the number of treatment days for each drug were added together and expressed as the total number of daily doses.

Hospitalisation The costs for hospitalisation were calculated as the number of days the patient spent in hospital multiplied by the unit cost for an inpatient day at the centre of admission. The cost of an inpatient day, also referred to as the 'the hotel cost', was defined as the basic cost, including food, accommodation, administration services, nursing and other staff costs.

Management by clinical specialists The costs for management by different types of clinical specialists were calculated according to the unit cost for each type of specialist and the number of consultations. For patients treated in inpatient care who were admitted for a duration of 1 week or longer between each study visit, a maximum number of one consultation per type of specialist was recorded for that period, with the exception of visits to family doctors and internists outside the hospital.

Topical treatment The costs for topical treatment were calculated for dressing material, staff who performed dressing changes and transportation. Staff costs were calculated for dressing changes performed by healthcare workers inside or outside the hospital. If the patient or a relative or a friend performed dressing changes, there were no staff costs. Material costs were calculated for all dressing changes and varied according to the type of dressing used. A specified list of dressings was included in the case record form; if 'other' dressing or 'not known' was indicated, the average cost of all other types of dressings used in that particular centre was used in the calculations. Transportation costs were calculated based on the information provided in the study entry form regarding the distance between the patient's home and the hospital. Transportation costs were included for all dressing changes that were performed by healthcare workers outside or inside the hospital. Thus, transportation costs are included in the analysis irrespective of whether it was the patient or a healthcare worker who travelled.

Indirect costs Indirect costs related to loss of production were analysed for patients who were employed and had been on sickness leave because of the foot ulcer. Costs were calculated by multiplying the number of weeks a patient had been on sickness leave by the average income per week of the general population in the country of residence.

Cost conversions and currency All costs are expressed in Euros $(€)$, according to the prices in 2005. If the unit cost for a specified resource was not available for 2005, the unit cost from another year was adjusted to give the price for 2005 using a country-specific consumer price index. Information about the consumer price index was collected from official statistics for each country or from the European Central Bank. Local currencies were converted into Euros using the official exchange rates for the end of 2005, obtained from the European Central Bank. In addition, costs were adjusted to account for differences in price levels between countries, using a volume index of gross domestic product (GDP) per capita in purchasing power standards. The viewpoint or perspective of the study is societal, i.e. both direct and indirect costs are considered, irrespective of the source of financing for the resources.

Statistical analyses Statistical analysis and cost calculations were performed using the SPSS statistical package, version 12.0.2 (SPSS, Chicago, IL, USA).

\section{Results}

Resource utilisation for management of diabetic foot ulcers

Resource utilisation for the different disease severity groups is shown in Table 2. The disease severity grouping is based 
Table 2 Resource utilisation in relation to ulcer severity score

\begin{tabular}{|c|c|c|c|c|c|c|}
\hline Resources & $\begin{array}{l}\text { Group A No } \\
\text { infection or PAD } \\
(n=245)\end{array}$ & $\begin{array}{l}\text { Group B With } \\
\text { infection, no PAD } \\
(n=276)\end{array}$ & $\begin{array}{l}\text { Group C No } \\
\text { infection, with } \\
\operatorname{PAD}(n=187)\end{array}$ & $\begin{array}{l}\text { Group D With both } \\
\text { infection and PAD } \\
(n=290)\end{array}$ & $\begin{array}{l}\text { Not } \\
\text { classified }^{\text {a }} \\
(n=71)\end{array}$ & $\begin{array}{l}\text { All patients } \\
\text { available for } \\
\text { evaluation } \\
(n=1,088)\end{array}$ \\
\hline \multicolumn{7}{|l|}{ In-hospital care } \\
\hline $\begin{array}{l}\text { Patients treated in } \\
\text { inpatient care }\end{array}$ & $55(22.4)$ & $118(42.8)$ & $86(46.0)$ & $199(68.6)$ & $39(43.3)$ & $497(45.7)$ \\
\hline $\begin{array}{l}\text { Hospital stay } \\
\text { (weeks) }\end{array}$ & $0.66(0-12)$ & $1.91(0-31)$ & $2.53(0-36)$ & $3.90(0-52)$ & $2.32(0-36$ & $2.30(0-52)$ \\
\hline \multicolumn{7}{|l|}{ Amputations } \\
\hline $\begin{array}{c}\text { Contralateral } \\
\text { amputation }\end{array}$ & $0.02(0-4)$ & $0.04(0-4)$ & $0.02(0-2)$ & $0.03(0-2)$ & $0.04(0-2)$ & $0.03(0-4)$ \\
\hline $\begin{array}{l}\text { Ipsilateral } \\
\text { amputation } \\
\text { below the ankle }\end{array}$ & $0.10(0-2)$ & $0.18(0-2)$ & $0.22(0-4)$ & $0.40(0-4)$ & $0.19(0-3)$ & $0.23(0-4)$ \\
\hline $\begin{array}{l}\text { Above the ankle } \\
\text { (lower leg) }\end{array}$ & $0.01(0-1)$ & $0.00(0-1)$ & $0.03(0-1)$ & $0.08(0-1)$ & $0.02(0-1)$ & $0.03(0-1)$ \\
\hline \multicolumn{7}{|c|}{ Other interventions and surgery } \\
\hline Revascularisation $^{\mathrm{b}}$ & $0.03(0-2)$ & $0.02(0-1)$ & $0.22(0-3)$ & $0.41(0-8)$ & $0.28(0-8)$ & $0.18(0-8)$ \\
\hline $\begin{array}{l}\text { All other } \\
\text { interventions and } \\
\text { surgery }^{c}\end{array}$ & $0.68(0-32)$ & $1.33(0-20)$ & $1.28(0-34)$ & $1.87(0-49)$ & $1.37(0-23)$ & $1.32(0-49)$ \\
\hline $\begin{array}{l}\text { Diagnostic } \\
\text { procedures and } \\
\text { investigations }^{\mathrm{d}}\end{array}$ & $2.24(0-18)$ & $3.20(0-23)$ & $3.35(0-25)$ & $4.54(0-22)$ & $4.00(0-25)$ & $3.43(0-25)$ \\
\hline \multicolumn{7}{|l|}{ Antibiotic therapy } \\
\hline $\begin{array}{l}\text { Patients treated } \\
\text { with antibiotics }\end{array}$ & $117(47.8)$ & $191(69.2)$ & $101(54.0)$ & $204(70.3)$ & $49(54.4)$ & $662(60.8)$ \\
\hline $\begin{array}{l}\text { Total number of } \\
\text { daily doses }\end{array}$ & $29.8(0-619)$ & $43.1(0-350)$ & $35.4(0-327)$ & $46.7(0-361)$ & $36.9(0-305)$ & $39.21(0-619)$ \\
\hline $\begin{array}{l}\text { Off-loading } \\
\text { footweare (pairs) }^{\text {e }}\end{array}$ & $1.90(0-11)$ & $2.40(0-15)$ & $2.29(0-14)$ & $2.38(0-12)$ & $2.14(0-20)$ & $2.24(0-20)$ \\
\hline Dressing changes & $74.3(0-349)$ & $69.2(0-336)$ & $74.4(0-355)$ & $79.0(0-348)$ & $70.7(0-337)$ & $73.98(0-355)$ \\
\hline \multicolumn{7}{|c|}{ Consultations/outpatient visits } \\
\hline $\begin{array}{l}\text { Medical } \\
\text { specialists }^{\mathrm{f}}\end{array}$ & $5.60(0-36)$ & $7.01(0-60)$ & $6.50(0-101)$ & $9.52(0-106)$ & $7.09(0-62)$ & $7.28(0-106)$ \\
\hline $\begin{array}{l}\text { Wound care } \\
\text { specialist }^{\mathrm{g}}\end{array}$ & $1.00(0-31)$ & $1.36(0-25)$ & $1.12(0-36)$ & $1.01(0-26)$ & $0.49(0-16)$ & $1.08(0-36)$ \\
\hline Paramedics ${ }^{\mathrm{h}}$ & $5.51(0-69)$ & $7.72(0-80)$ & $6.72(0-91)$ & $7.50(0-106)$ & $12.10(0-133)$ & $7.35(0-133)$ \\
\hline $\begin{array}{l}\text { Sickness leave } \\
\text { (weeks) }\end{array}$ & $1.37(0-38)$ & $2.38(0-39)$ & $0.78(0-43)$ & $0.72(0-34)$ & $0.74(0-24)$ & $1.30(0-43)$ \\
\hline
\end{tabular}

Values are presented as average number (range) of procedures per patient, except those for patients treated with inpatient care and antibiotics, which are presented as $n(\%)$

${ }^{a}$ Overall there were 71 patients who could not be linked to any of the four types of severity score

${ }^{\mathrm{b}}$ Revascularisation: vascular surgery, percutaneous transluminal angioplasty

${ }^{\mathrm{c} O t h e r}$ interventions and surgery: surgical debridement, plastic surgery, orthopaedic surgery, other surgery

${ }^{\mathrm{d}}$ Diagnostic procedures and interventions: pressure platform, toe pressure, ankle pressure, transcutaneous $\mathrm{O}_{2}$ pressure measurement, duplex Doppler ultrasound, $\mathrm{x}$-ray, contrast angiography, scintigram, magnetic resonance angiography, magnetic resonance imaging, computed tomography scan, bone biopsy, microbiology

'Off-loading: temporary footwear, orthopaedic shoes, total contact cast, insoles, orthoses, other casts

${ }^{\mathrm{f}}$ Medical specialist: family doctor, internist working inside or outside hospital, diabetologist, general surgeon, vascular surgeon, orthopaedic surgeon, plastic surgeon, infectious disease specialist, radiologist, dermatologist, rehabilitation specialist

${ }^{\mathrm{g}}$ Wound care specialist: either medical specialist or paramedics, according to local practice

${ }^{\mathrm{h}}$ Paramedics: podiatrist or chiropodist, orthopaedic shoemaker or orthotist, cast technician, diabetic nurse, district nurse or home-care nurse, dietitian 
on the presence or absence of PAD and/or infection at baseline, as follows: group A, patients without infection and PAD; group $\mathrm{B}$, patients with infection but without PAD; group $\mathrm{C}$, patients with PAD but without infection; and group $\mathrm{D}$, patients with both infection and PAD. A number of patients $(n=71)$ could not be placed in any disease severity score group because of missing data. In general, the average number of procedures used for diagnosis and investigations was low. Microbiology was the most frequently used diagnostic procedure and temporary footwear and orthopaedic shoes were the most frequently used offloading techniques in all groups (data not shown). There were large differences in resource use between individual patients, as illustrated by the large ranges shown for many of the variables. The percentage of patients treated in inpatient care was relatively high, ranging from $22 \%$ of patients in the group with the least severe disease (group A) to $67 \%$ of patients with both infection and PAD (group D). Not surprisingly, treatment with antibiotics was most frequent in the group of patients with infection but without PAD (group B, 69\%) and patients with both infection and PAD (group D, $70 \%$ ) but was common in all outcome groups. Consultations with medical specialists and paramedics were also frequent in all groups.
Costs of diabetic foot ulcers

The total treatment cost per patient in relation to disease severity is illustrated in Table 3. In all disease severity groups, the costs of hospitalisation and antibiotics represented a large part of the total direct costs. In addition, the average costs of amputation, revascularisation and other interventions and surgery were high in patients with both infection and PAD (group D). For patients in the group with most severe disease (group D), the average total costs were almost four times as high as those for patients with the least severe disease (group A). On the other hand, the indirect costs were higher in the two groups with the least severe disease (groups A and B) than in those more severe disease (groups $\mathrm{C}$ and D). This can be explained by the greater frequency of employment among patients with less severe disease; the employment rate for groups $\mathrm{A}$ and $\mathrm{B}$ combined was $39 \%$ vs $11 \%$ for groups $\mathrm{C}$ and $\mathrm{D}$ together $(p<0.01)$.

The cost pattern between different types of resources shown in Table 3 is similar to that observed when costs are related to the clinical outcome over the 1 year study period (Table 4). The highest costs in all outcome groups were for hospitalisation. Other resources with high costs were surgery, 'other interventions' and antibiotics. In patients

Table 3 Resource utilisation in relation to ulcer severity score

\begin{tabular}{|c|c|c|c|c|c|c|}
\hline Resource use & $\begin{array}{l}\text { Group A No } \\
\text { infection or } \\
\text { PAD }(n=204)\end{array}$ & $\begin{array}{l}\text { Group B With } \\
\text { infection, no } \\
\text { PAD }(n=208)\end{array}$ & $\begin{array}{l}\text { Group C No } \\
\text { infection, with } \\
\text { PAD }(n=153)\end{array}$ & $\begin{array}{l}\text { Group D With both } \\
\text { infection and PAD } \\
(n=185)\end{array}$ & $\begin{array}{l}\text { Not } \\
\text { classified }^{\text {a }} \\
(n=71)\end{array}$ & $\begin{array}{l}\text { All patients } \\
\text { included in costing } \\
\text { analysis }(n=821)\end{array}$ \\
\hline \multicolumn{7}{|l|}{ Direct costs } \\
\hline $\begin{array}{l}\text { Hospitalisation } \\
\text { (hotel cost) }\end{array}$ & $808(18)$ & $3,703(40)$ & $4,433(45)$ & $6,787(40)$ & $4,599(40)$ & $3,892(39)$ \\
\hline Amputations & $198(4)$ & $499(5)$ & $594(6)$ & $2,411(14)$ & $687(6)$ & $889(9)$ \\
\hline Revascularisation & $44(1)$ & $62(1)$ & $685(7)$ & $1309(8)$ & $1,213(11)$ & $554(5)$ \\
\hline $\begin{array}{l}\text { Other } \\
\text { interventions } \\
\text { and surgery }\end{array}$ & $550(12)$ & $992(11)$ & $897(9)$ & $1,553(9)$ & $937(8)$ & $986(10)$ \\
\hline $\begin{array}{l}\text { Diagnostic } \\
\text { procedures and } \\
\text { investigations }\end{array}$ & $74(2)$ & $111(1)$ & $190(2)$ & $260(2)$ & $225(2)$ & $160(2)$ \\
\hline Antibiotics & 847 (19) & $1,146(12)$ & $1,147(12)$ & $1,846(11)$ & $764(7)$ & $1,197(12)$ \\
\hline $\begin{array}{l}\text { Off-loading/ } \\
\text { orthopaedic } \\
\text { appliances }\end{array}$ & $435(10)$ & $448(5)$ & $447(5)$ & $503(3)$ & $445(4)$ & $457(5)$ \\
\hline Topical treatment & $368(8)$ & $446(5)$ & $679(7)$ & $1,057(6)$ & $1,029(9)$ & $658(7)$ \\
\hline $\begin{array}{l}\text { Consultations/ } \\
\text { outpatient visits }\end{array}$ & $448(10)$ & $707(8)$ & $549(6)$ & $687(4)$ & $1,221(11)$ & $653(6)$ \\
\hline Total direct costs & 3,771 & 8,113 & 9,622 & 16,414 & 11,120 & 9,446 \\
\hline Indirect costs & $743(16)$ & $1,160(13)$ & $229(2)$ & $421(3)$ & $335(3)$ & $645(6)$ \\
\hline $\begin{array}{l}\text { Total direct and } \\
\text { indirect cost }\end{array}$ & $4,514(100)$ & $9,273(100)$ & $9,851(100)$ & $16,835(100)$ & $11,455(100)$ & $10,091(100)$ \\
\hline
\end{tabular}

The direct and indirect costs per patient with diabetic foot ulcers are presented in Euros (\% of total), according to 2005 prices, and have been weighted by purchasing power standards. Out of the 1,088 patients who were available for evaluation, 821 were included in the costing analysis ${ }^{\mathrm{a}}$ Overall there were 71 patients who could not be linked to any of the four types of severity score 
Table 4 Direct and indirect costs per patient in relation to outcome

\begin{tabular}{lcccc}
\hline Resource use & $\begin{array}{l}\text { Healed } \\
(n=647)\end{array}$ & $\begin{array}{l}\text { Deceased, unhealed } \\
(n=34)\end{array}$ & $\begin{array}{l}\text { Major amputation } \\
(n=36)\end{array}$ & $\begin{array}{l}\text { Not healed within } \\
12 \text { months } \\
(n=104)\end{array}$ \\
\hline Direct costs & & & & \\
Hospitalisation (hotel cost) & $2,647(34)$ & $4,771(55)$ & $10,953(43)$ & $8,907(44)$ \\
Amputations & $602(8)$ & $498(6)$ & $6,907(27)$ & $718(4)$ \\
Revascularisation & $538(7)$ & $238(3)$ & $624(2)$ & $734(4)$ \\
Other interventions and surgery & $712(9)$ & $949(11)$ & $2,894(11)$ & $2,042(10)$ \\
Diagnostic procedures and & $126(2)$ & $104(1)$ & $289(1)$ & $345(2)$ \\
$\quad$ investigations & & & $1,208(5)$ & $360(1)$ \\
Antibiotics & $1,060(14)$ & $959(11)$ & $922(4)$ & $636(3)$ \\
Off-loading/orthopaedic appliances & $449(6)$ & $165(2)$ & $383(2)$ & $1,780(9)$ \\
Topical treatment & $473(6)$ & $470(5)$ & 24,540 & $1,508(8)$ \\
Consultations/outpatient visits & $540(7)$ & $473(5)$ & $681(3)$ & 18,790 \\
Total direct costs & 7,147 & 8,628 & $25,222(100)$ & $20,064(100)$ \\
Indirect costs & $574(7)$ & $25(0)$ & $8,653(100)$ & \\
Total direct and indirect cost & $7,722(100)$ & & & \\
\hline
\end{tabular}

The direct and indirect costs per patient with diabetic foot ulcers are presented in Euros ( $\%$ of total), according to 2005 prices, and have been weighted by purchasing power standards. Out of the 1,088 patients who were available for evaluation, 821 were included in the costing analysis

whose ulcers did not heal within the observation period of 12 months, the costs of topical treatment and consultations were high, highlighting the influence of treatment duration for these types of resources. The highest total costs were found in patients who had undergone major amputations, and lowest in the group of patients whose ulcer healed. The costs of diagnostic procedures, investigations, off-loading and orthopaedic appliances were rather low in all groups, irrespective of disease severity or outcome (Tables 3 and 4).

\section{Discussion}

In this study we have collected prospective data on resource use and costs associated with the treatment of diabetic foot ulcers. Costs are high, the average total for direct and indirect cost being approximately $€ 10,000$, based on the costing data of 821 patients from the participating countries. Importantly, resource utilisation and costs varied between the different outcome groups and between individuals with and without PAD and/or infection at baseline.

The average costs reported in this study cannot easily be compared with data published in the current literature in view of the differences with respect to included patients, duration of follow-up and methods for analyses. The data may be compared with the single-centre data from Sweden, reported in the early 1990s, in which costs for primary healing of the ulcer were approximately US $\$ 8,950$ [15], which is about $€ 7,412$ according to 2005 prices. The results reported by an American group, based on medical and pharmaceutical claims data from 2000 and 2001, included both in- and outpatients with and without PAD. The average direct cost per ulcer episode was US $\$ 13,179$ (approximately $€ 10,914)$, ranging from US\$5,218 (€4,321) in patients with adequate vascular status to US\$23,372 $(€ 19,357)$ in individuals with inadequate vascular status [16]. In the present European study, costing data are derived from several countries, including both low- and high-cost countries, although costs were weighted by purchasing power standards to compensate for this. These data very clearly demonstrate that treatment of diabetic foot disease is a major determinant of diabetes-related resource utilisation and costs throughout Europe. Based on the data for Europe for 2003, which showed a prevalence of diabetes of 48 million people and an ulcer incidence among diabetic patients of $2 \%$ per year [1], the costs associated with the treatment of diabetic foot ulcers may be as high as ten billion Euros per year.

It is clear from the present study that the costs for the treatment of individuals with PAD, especially in combination with infection, are substantially higher than those for the treatment of patients without PAD. Only a small proportion of this difference is attributable to higher costs for diagnostic procedures. Most of the excess costs in individuals with PAD and infection are related to a higher rate of hospitalisation and higher costs of antibiotics, amputations, revascularisation and other surgery. We have previously demonstrated that characteristics and predictors of outcome are very different in patients with and without PAD, which suggests that these conditions should be regarded as separate disease states [2]. The resource and cost data reported here support this concept. Habacher et al. [7] recently published retrospective data on a group of 89 patients from an Austrian tertiary referral hospital in which similar differences between patients with and without PAD 
and/or infection were observed. They reported costs for the patients with foot ulcers but without PAD and infection of $€ 1,071$ vs $€ 7,844$ for the patients with both PAD and infection. However, the costs for the latter group were less than $50 \%$ of those for the corresponding group in our cohort. This difference may be related to differences in costing between the studies, for example, it is unclear whether staff costs for dressing changes in outpatient care were included in the Austrian study.

In the current study, the majority of costs for the treatment of diabetic foot disease were related to hospital admissions. In the Eurodiale Study, $27 \%$ of the patients were admitted at baseline [11] and a number of patients were admitted during follow-up. In view of the magnitude of these costs, reducing the number and duration of hospital admissions seems an attractive option for decreasing the costs associated with the treatment of diabetic foot disease. The hospital admissions are usually related to progressive tissue loss in the context of PAD and/or infection. We think that strategies aimed at early referral, timely institution of antibiotic therapy and early vascular intervention may help to prevent progressive tissue loss, thereby reducing admission rates. The development of such strategies should be one of the main priorities in diabetic foot care over the next years.

The costs for lower leg amputations in this study are not completely comparable with those reported by previous studies. One possible explanation for this is that patients who underwent a lower leg amputation in the present study were only followed until this amputation was performed, whereas in previous Swedish studies, patients were followed and costs calculated until the amputated leg was completely healed $[15,17]$. Similarly, the cost of a lower leg amputation reported by the recent Australian study is considerably lower than that reported by the present study, mainly because only inpatient costs were included in their analyses [6]. Patients included in the present study who underwent minor amputations below the ankle, which subsequently healed, were classified as healed patients, whereas the costs of minor amputations were presented separately in the previous Swedish studies $[15,17]$. The total average costs for patients classified as healed are therefore probably higher than if patients who had undergone a minor amputation had not been included in this group.

In the present study the average costs of antibiotics constituted between $11 \%$ and $14 \%$ of the total direct costs for patients with infection, despite the fact that some antibiotic use was probably not reported. The number of patients with infection reported to be treated with antibiotics was significantly less than $100 \%$. These costs are much higher than those reported by a Swedish study in which the share of costs for antibiotics was 4.5\% [17]. One reason for this discrepancy in costs could be the use of more expensive antibiotics, more parenteral drugs and longer treatment periods across 2003-2004 compared with the early 1990s. Moreover, policies for the prescription of antibiotics can differ substantially between countries, stressing the importance of performing multinational studies.

One limitation of the study is that unit cost data could not be calculated for all participating countries because of the lower number of patients enrolled and difficulties in obtaining data on certain resources in some countries. Cost calculations were possible for seven of the ten countries or $75 \%$ of the patients included. Difficulties in collecting reliable unit costs have previously been described and should not be neglected when planning health-economic studies [18]. These difficulties also indicate the importance of reporting resource utilisation in terms of physical quantities (e.g. two dressings, two bypasses). Another limitation is that the analyses of resource utilisation and costs do not include the total resources used for the management of diabetic foot disease because patients could have been treated for their present foot ulcer at a different centre before being included in the study. Thus, the actual values for resource use and costs are probably higher than reported in this article, but, in general, it is too difficult to accurately obtain information on treatment retrospectively. The study is also limited by the fact that recurrent ulcers were excluded, and that a proportion of the cohort (although less than a third) were tertiary referrals to specialised centres, which may treat more complex patients. Finally, any cost of treatment study is limited by the incomplete generalisability of economic data or transferability of results from one country to another [19]. Treatment costs are, amongst other things, influenced by differences in the availability of healthcare resources and variations in clinical practice, together with differences in incentives given to healthcare professionals. As described elsewhere, we found significant variations in clinical practice between centres. In particular, there were marked differences in the use of resources such as total contact casting and vascular imaging [20]. In addition, the relative prices and costs may vary between countries. This problem has at least partly been circumvented in the present study by the conversion of local costs into purchasing power standards.

Although the current study is subject to several weaknesses, as described above, a strength was the relatively large cohort monitored prospectively in daily clinical practice until a predefined treatment outcome or study end date was reached, with no predetermined intervention options. Ten European countries participated in the resource use analysis and data from seven countries and ten centres were available for the cost analysis. The perspective of the study was societal, including both direct and indirect costs, irrespective of payers and reimbursement systems in the participating countries. The present information illustrates the magnitude of the problem in economic terms for 
decision makers both within and outside the healthcare system. Moreover, it can help us to define target groups for whom an improvement in care could result in major savings in healthcare expenditure. Up to now many publications in the field of diabetic foot disease have focused on wound healing in patients with a neuropathic foot ulcer, the group with the lowest costs in our analyses. Although several studies on the treatment of infection have been published, patients with PAD were usually excluded or not specifically analysed in these studies. Our data suggest that to reduce the high costs of diabetic foot disease, major efforts should be undertaken to improve the treatment in this subgroup of patients, who have the highest costs and the poorest outcome.

This health-economic study is mainly descriptive, but the database constructed could be a valuable resource for future health-economic model simulations, allowing the cost-effectiveness of different management strategies to be evaluated. Such studies may be helpful to achieve a more cost-effective use of the resources in healthcare and society in general.

Acknowledgements This study was supported by the fifth framework programme of the European Commission. We would like to thank all Eurodiale coworkers: M. Annersten, R. Bem, A. Boykowskov, H. Brill, S. Bus, A. De Leiva, J. De Neve, S. Di Cario, V. Fejfarova, J. Gaitan, D. Geenen, T. Geens, L. Giurato, B. Hempe, M. Hutten, J. Kersken, F. Palumbo, L. Rizzo, R Roel, D. Simon, M. Slak.

Duality of interest The authors declare that there is no duality of interest associated with this manuscript.

Open Access This article is distributed under the terms of the Creative Commons Attribution Noncommercial License which permits any noncommercial use, distribution, and reproduction in any medium, provided the original author(s) and source are credited.

\section{References}

1. Boulton AJ, Vileikyte L, Ragnarson-Tennvall G, Apelqvist J (2005) The global burden of diabetic foot disease. Lancet 366:1719-1724

2. Prompers L, Schaper N, Apelqvist J et al (2008) Prediction of outcome in individuals with diabetic foot ulcers: focus on the differences between individuals with and without peripheral arterial disease. The EURODIALE Study. Diabetologia 51:747-755

3. Apelqvist J, Ragnarson-Tennvall G, Larsson J, Persson U (1995) Long-term costs for foot ulcers in diabetic patients in a multidisciplinary setting. Foot Ankle Int 16:388-394

4. Apelqvist J (1998) Wound healing in diabetes. Outcome and costs. Clin Podiatr Med Surg 15:21-39
5. Ragnarson Tennvall G, Apelqvist J (2004) Health-economic consequences of diabetic foot lesions. Clin Infect Dis 39(Suppl 2):S132S139

6. Davis WA, Norman PE, Bruce DG, Davis TM (2006) Predictors, consequences and costs of diabetes-related lower extremity amputation complicating type 2 diabetes: the Fremantle Diabetes Study. Diabetologia 49:2634-2641

7. Habacher W, Rakovac I, Gorzer E et al (2007) A model to analyse costs and benefit of intensified diabetic foot care in Austria. J Eval Clin Pract 13:906-912

8. Girod I, Valensi P, Laforet C, Moreau-Defarges T, Guillon P, Baron F (2003) An economic evaluation of the cost of diabetic foot ulcers: results of a retrospective study on 239 patients. Diabetes Metab 29:269-277

9. Smith D, Cullen MJ, Nolan JJ (2004) The cost of managing diabetic foot ulceration in an Irish hospital. Ir J Med Sci 173:89-92

10. Matricali GA, Dereymaeker G, Muls E, Flour M, Mathieu C (2007) Economic aspects of diabetic foot care in a multidisciplinary setting: a review. Diabetes Metab Res Rev 23:339-347

11. Prompers L, Huijberts M, Apelqvist J et al (2007) High prevalence of ischaemia, infection and serious comorbidity in patients with diabetic foot disease in Europe. Baseline results from the Eurodiale Study. Diabetologia 50:18-25

12. Prompers L, Huijberts M, Apelqvist J et al (2007) Optimal organization of health care in diabetic foot disease: introduction to the Eurodiale Study. Int J Low Extrem Wounds 6:11-17

13. Schaper NC (2004) Diabetic foot ulcer classification system for research purposes: a progress report on criteria for including patients in research studies. Diabetes Metab Res Rev 20(Suppl 1): S90-S95

14. Armstrong DG, Lavery LA, Harkless LB (1998) Validation of a diabetic wound classification system. The contribution of depth, infection, and ischemia to risk of amputation. Diabetes Care 21:855859

15. Apelqvist J, Ragnarson-Tennvall G, Persson U, Larsson J (1994) Diabetic foot ulcers in a multidisciplinary setting. An economic analysis of primary healing and healing with amputation. J Intern Med 235:463-471

16. Stockl K, Vanderplas A, Tafesse E, Chang E (2004) Costs of lower-extremity ulcers among patients with diabetes. Diabetes Care 27:2129-2134

17. Ragnarson Tennvall G, Apelqvist J, Eneroth M (2000) The inpatient care of patients with diabetes mellitus and foot ulcers. A validation study of the correspondence between medical records and the Swedish Inpatient Registry with the consequences for cost estimations. J Intern Med 248:397-405

18. Schulman K, Burke J, Drummond M et al (1998) Resource costing for multinational neurologic clinical trials: methods and results. Health Econ 7:629-638

19. Drummond M, Pang F (2001) Transferability of economic evaluation results. Economic evaluation in health care. Oxford University Press, Oxford

20. Prompers L, Huijberts M, Apelqvist J et al (2008) Delivery of care to diabetic foot ulcer patients in daily practice: Results of the Eurodiale Study, a prospective cohort study. Diabet Med 25:700-707 